\title{
Associations between palliative chemotherapy and adult cancer patients' end of life care and place of death: prospective cohort study
}

\author{
(c) (1) (8) OPEN ACCESS
}

\author{
Alexi A Wright assistant professor of medicine ${ }^{1}$, Baohui Zhang research statistician ${ }^{2}$, Nancy L \\ Keating associate professor of medicine and health care policy ${ }^{3}$, Jane C Weeks professor of \\ medicine ${ }^{1}$, Holly G Prigerson professor of medicine ${ }^{2}$
}

${ }^{1}$ Harvard Medical School, Department of Medical Oncology, Dana-Farber Cancer Institute, Dana 1133, 450 Brookline Avenue, Boston, MA 02215, USA; ${ }^{2}$ Center for End-of-Life Research, Weill Cornell Medical College, New York, NY 10065, USA; ${ }^{3}$ Harvard Medical School, Department of Health Care Policy, 180 Longwood Avenue, Boston, MA 02115, USA

\begin{abstract}
Objectives To determine whether the receipt of chemotherapy among terminally ill cancer patients months before death was associated with patients' subsequent intensive medical care and place of death.

Design Secondary analysis of a prospective, multi-institution, longitudinal study of patients with advanced cancer

Setting Eight outpatient oncology clinics in the United States.

Participants 386 adult patients with metastatic cancers refractory to at least one chemotherapy regimen, whom physicians identified as terminally ill at study enrollment and who subsequently died.

Main outcome measures Primary outcomes: intensive medical care (cardiopulmonary resuscitation, mechanical ventilation, or both) in the last week of life and patients' place of death (for example, intensive care unit). Secondary outcomes: survival, late hospice referrals ( $\leq 1$ week before death), and dying in preferred place of death.
\end{abstract}

Results $216(56 \%)$ of 386 terminally ill cancer patients were receiving palliative chemotherapy at study enrollment, a median of 4.0 months before death. After propensity score weighted adjustment, use of chemotherapy at enrollment was associated with higher rates of cardiopulmonary resuscitation, mechanical ventilation, or both in the last week of life (14\% v $2 \%$; adjusted risk difference $10.5 \%, 95 \%$ confidence interval $5.0 \%$ to $15.5 \%$ ) and late hospice referrals $(54 \%$ v $37 \% ; 13.6 \%$, $3.6 \%$ to $23.6 \%$ ) but no difference in survival (hazard ratio $1.11,95 \%$ confidence interval 0.90 to 1.38). Patients receiving palliative chemotherapy were more likely to die in an intensive care unit $(11 \% \mathrm{~V}$ $2 \%$; adjusted risk difference $6.1 \%, 1.1 \%$ to $11.1 \%$ ) and less likely to die at home $(47 \%$ v $66 \% ;-10.8 \%,-1.0 \%$ to $-20.6 \%)$, compared with those who were not. Patients receiving palliative chemotherapy were also less likely to die in their preferred place, compared with those who were not (65\% v $80 \%$; adjusted risk difference $-9.4 \%,-0.8 \%$ to $-18.1 \%$ ).

Conclusions The use of chemotherapy in terminally ill cancer patients in the last months of life was associated with an increased risk of undergoing cardiopulmonary resuscitation, mechanical ventilation or both and of dying in an intensive care unit. Future research should determine the mechanisms by which palliative chemotherapy affects end of life outcomes and patients' attainment of their goals

\section{Introduction}

Chemotherapy is used to treat metastatic cancer, with the goal of palliating symptoms and improving survival. Between $20 \%$ and $50 \%$ of patients with incurable cancers receive chemotherapy within 30 days of death, ${ }^{12}$ despite growing concerns that it may not be effective. Recently, the American Society for Clinical Oncology identified end of life chemotherapy as one of the "top five" practices that could improve patients' care and reduce costs, if stopped. ${ }^{3}$ Deciding when to discontinue chemotherapy is often challenging, however, given limited data on whether chemotherapy is helpful or harmful in the final months of life. ${ }^{2-5}$

Research suggests that the use of chemotherapy within two weeks of death is associated with lower rates of hospice use, ${ }^{67}$ but only $6.2 \%$ of patients receive chemotherapy this late. ${ }^{8}$ Most decisions about treatment occur months before death, when data to guide decision making about chemotherapy are more limited. For example, in a randomized controlled study comparing early palliative care integrated with oncology care versus standard oncology care among patients newly diagnosed as having metastatic lung cancer, Greer et al found that $62 \%$ of all enrolled 
patients received chemotherapy within two months of death. ${ }^{9}{ }^{10}$ However, patients who received concurrent palliative and oncologic care stopped intravenous chemotherapy an average of two months earlier than did those in the standard oncology group but had a longer median overall survival and were more likely to receive at least one week of hospice services. ${ }^{9}{ }^{10}$ To our knowledge, however, Greer at al's study and others have not specifically examined whether the use of chemotherapy in the months leading up to the patient's death is associated with the subsequent receipt of intensive medical care in the last week of life or death in an intensive care unit.

In this secondary analysis of Coping with Cancer data, ${ }^{11}$ we sought to determine whether terminally ill cancer patients who were receiving chemotherapy at study enrollment were more likely to receive intensive medical care in the last week of life and die in an intensive care unit, compared with those who were not. We hypothesized that palliative chemotherapy would be associated with more intensive medical care (for example, cardiopulmonary resuscitation, mechanical ventilation, or both) and late referrals to a hospice, as chemotherapy is often an exclusion criterion for hospice admission, ${ }^{12}$ and oncologists express reluctance about discussing advance care planning while prescribing chemotherapy. ${ }^{14-16}$ Similarly, we expected that patients receiving palliative chemotherapy would be less likely to die where they wanted to, as oncologists often delay discussing patients' preferred site of death, compared with other non-cancer specialists. ${ }^{14}$

\section{Methods}

Coping with Cancer was a federally funded, prospective, longitudinal, multi-institution cohort study of terminally ill cancer patients and their informal caregivers, which was designed to examine how psychosocial factors influence patients' medical care and caregivers' adjustment to bereavement. ${ }^{11}$ Of 917 eligible patients, 638 (69.6\%) consented and enrolled in Coping with Cancer. The three most common reasons for non-participation were "not interested" $(n=120)$, "other" ( $n=69)$, and "caregiver refuses" $(n=37)$. Participants were more likely than non-participants to be Hispanic (12\% (75/638) v 6\% (16/279), $\mathrm{P}=0.006)$, but otherwise did not differ by sociodemographic characteristics.

This report describes 386 patients who were recruited between October 2002 and February 2008 and died during the course of the study, such that we could analyze their end of life medical care. We excluded participants in clinical trials $(n=37)$, as their treatment preferences and therapeutic expectations often differ from those of patients receiving standard chemotherapy or supportive care. ${ }^{17}$ Patients who had died as of February 28, 2008 did not differ significantly in type of cancer or receipt of chemotherapy from participants who lived. However, decedents had worse performance status, more symptoms, and greater awareness of terminal illness and were more likely to be male, unmarried, uninsured, less educated, younger, and non-white (all $\mathrm{P}<0.05$ ).

Participating sites included Yale Cancer Center, the Veterans Affairs Connecticut Healthcare System Comprehensive Cancer Clinics, the Parkland Hospital Palliative Care Service, Simmons Comprehensive Cancer Center, Massachusetts General Hospital, Dana-Farber Cancer Institute, Memorial Sloan Kettering Cancer Center, and New Hampshire Oncology-Hematology. The Dana-Farber/Harvard Cancer Center's Office for Human Research Studies coordinated the study, and all patients provided written informed consent.
Patients were eligible to participate if they had metastatic cancer that had progressed through at least one chemotherapy regimen, had a physician formulated prognosis of six months or less to live, were aged at least 20 years, had an informal caregiver, and were assessed by clinic staff and interviewer as having adequate stamina to complete the interview. We excluded patient-caregiver dyads in which either the patient or the caregiver refused to participate, met criteria for dementia or delirium (by neurobehavioral cognitive status examination), or did not speak either English or Spanish.

Patients participated in a baseline interview in English or Spanish for a $\$ 25(£ 15 ; € 18)$ payment at a time that was close to when decisions about chemotherapy were being made. We reviewed medical charts at the time of study enrollment and recorded current use of chemotherapy. Research assistants confirmed patients' performance status and prognosis of six months or less with physicians. We did not record the number and length of previous and subsequent treatments. After each patient's death, we conducted a chart review and postmortem interview with the patient's caregivers to confirm the medical care received at the end of life, the patient's place of death, and whether the patient died in his or her preferred place of death.

\section{Main outcome measures}

The primary outcomes were end of life treatment and location of death. We determined use of intensive interventions in the last week of life (that is, cardiopulmonary resuscitation, mechanical ventilation, or both) and location of death (intensive care unit, hospital, nursing home, inpatient hospice, or home) through a medical chart review and interviews with caregivers.

\section{Secondary outcome measures}

Survival-We abstracted the time from study enrollment to death from medical charts.

Late hospice referrals-We determined the duration of hospice services through chart review and interviews with caregivers. We defined late referrals to a hospice as one week or less before death. ${ }^{11}$

Attainment of preferred place of death-In postmortem interviews, we asked caregivers, "Do you think that the place of death was where the patient would have most wanted to die?" Patients whose caregivers responded "yes" were designated as having died where they wanted to.

\section{Primary independent variable of interest}

We reviewed medical charts on study enrollment to determine whether patients were receiving chemotherapy, radiation, pain management, or treatment on a clinical trial at the time of enrollment. Patients receiving chemotherapy as any part of their treatment, outside of a clinical trial, were included in the chemotherapy group.

\section{Additional covariates measured at baseline}

Sociodemographic characteristics - Patients reported sex, age, marital status, race/ethnicity, religion, health insurance coverage, and last grade completed in school.

Health status measures-We measured patients' functional status with the Karnofsky score and Eastern Cooperative Oncology Group (ECOG) performance status, ${ }^{18}$ comorbid medical conditions with the Charlson Comorbidity Index,${ }^{19}$ and quality of life with the McGill Quality of Life Index. ${ }^{20}$. communication, and advance care planning - We used validated 
measures to elicit patients' preferences for chemotherapy, mechanical ventilation, admission to an intensive care unit near death, and life extending care versus comfort care. ${ }^{21}{ }^{22} \mathrm{We}$ also assessed patients' acknowledgment of terminal illness, as this has been associated with higher rates of advance care planning and hospice use..$^{23}$ The Brief COPE and RCOPE surveys assessed active, emotion focused, maladaptive, and positive religious coping with cancer related stress. ${ }^{24}$ We also asked patients whether they recalled having an end of life discussion with their physician, ${ }^{11}$ had a strong therapeutic alliance with their providers, ${ }^{25}$ and had completed a living will, durable power of attorney, or do not resuscitate order (see web appendix).

\section{Statistical analyses}

We used $t$ test, $\chi^{2}$, and Fisher's exact statistics, as appropriate, to test for significant associations between patients' baseline characteristics and the receipt of chemotherapy at study enrollment. We used multiple imputation to impute missing data for items other than the dependent variables (for which no data were missing in our cohort) ${ }^{26}$; item non-response was less than $14 \%$ for all variables.

We used propensity score analyses to assess the association between patients who were or were not receiving chemotherapy at the time of enrollment. ${ }^{27}$ To do the propensity score analysis, we first used logistic regression to assess the association of all measured demographic, clinical, psychosocial, and institutional characteristics with being treated with chemotherapy at baseline. The model included age, sex, marital status, insurance status, education, race/ethnicity, religion, institution, cancer type, Karnofsky and ECOG scores, Charlson Comorbidity Index, McGill Quality of Life Index subscales, patients' treatment preferences and advance care planning, terminal illness acknowledgment, therapeutic alliance with physicians, end of life discussions, and coping styles. For each patient, we used the regression coefficients and the observed covariates to calculate the propensity to receive chemotherapy at study enrollment and derived individual weights equal to the probability of belonging to the opposite group (that is, not receiving chemotherapy). ${ }^{11}{ }^{28}$ Thus, after propensity adjustment the weighted distribution of characteristics in both groups were balanced. We then used a generalized linear regression model with an identity link function and a binomial distribution, with the propensity weighted cohorts, to estimate the association of chemotherapy with binary outcomes (for example,

cardiopulmonary resuscitation and/or mechanical ventilation). Our events were rare, so we calculated and reported our results as adjusted risk differences as odds ratios may exaggerate the actual risk. We did a sensitivity analysis to examine the effect of excluding covariates that might change over time (Karnofsky score, ECOG score, McGill Quality of Life scales, treatment preferences, and terminal illness awareness), as the exact date of starting palliative chemotherapy was not ascertained during the baseline assessment. We used Cox proportional hazard models to compare the overall survival of patients who were receiving palliative chemotherapy with those who were not, with adjustment for propensity weights.

We used SOLAS for Missing Data Analysis version 4.0 for multiple imputation and SAS version 9.2 for statistical analyses. We present two sided $P$ values without adjustment for multiple comparisons; we considered $\mathrm{P}<0.05$ to be significant.

\section{Results}

The cohort consisted of 386 terminally ill cancer patients who died a median of 4.0 (interquartile range 1.8-8.3) months after enrollment in the study. Overall, $56.0 \%$ of participants were receiving palliative chemotherapy on study enrollment. As shown in table $1 \Downarrow$, patients who were receiving palliative chemotherapy were more likely to be younger, married, insured, and better educated and to have better performance status, overall quality of life, physical functioning, and psychological wellbeing compared with patients who were not receiving chemotherapy (all $\mathrm{P} \leq 0.04$ ). They were also more likely to express a preference to receive "life extending" care over comfort care $(39 \% v 26 \%, \mathrm{P}=0.01)$, including chemotherapy if it might extend their life by one week $(86 \% v 60 \%, \mathrm{P}<0.001)$, compared with those not receiving chemotherapy.

Patients receiving palliative chemotherapy were less likely to acknowledge that their illness was terminal (35\% v 49\%, $\mathrm{P}=0.04)$ and to report having discussed their end of life wishes with a physician $(37 \% v 48 \%, \mathrm{P}=0.03)$, compared with those who were not. They were also less likely to have completed a do not resuscitate order $(36 \% v 49 \%, \mathrm{P}<0.05)$. Propensity score weighting successfully balanced all of the observed differences in patients' characteristics between the two groups (table $1 \Downarrow$ ).

In propensity score weighted analyses, receipt of chemotherapy at enrollment was associated with significantly more intensive medical interventions near death. As shown in table $2 \Downarrow$, patients receiving palliative chemotherapy were more likely to receive cardiopulmonary resuscitation, mechanical ventilation, or both in the last week of life (14\% v 2\%; adjusted risk difference $10.5 \%, 95 \%$ confidence interval $5.0 \%$ to $15.5 \%$ ) compared with those who were not. Chemotherapy use was also associated with higher rates of use of a feeding tube in the last week $(11 \% \mathrm{v}$ $5 \%$; adjusted risk difference $7.1 \%, 1.7 \%$ to $12.5 \%$ ) and of late hospice referrals (54\% v 37\% enrolled within one week of death; $13.6 \%, 3.6 \%$ to $23.6 \%$ ). In adjusted Cox proportional hazards models, we found no significant difference in overall survival between patients who were receiving palliative chemotherapy at study enrollment and those who were not (hazard ratio 1.11, $95 \%$ confidence interval 0.90 to 1.38 ). In a secondary model, we assessed the association between receipt of palliative chemotherapy and the intensity of end of life medical care without including characteristics that might have changed since the decision to start palliative chemotherapy was made (that is, performance status, quality of life, treatment preferences, and terminal illness acknowledgment), and the results did not change.

As shown in table $3 \Downarrow$, patients who received chemotherapy at enrollment were more likely to die in an intensive care unit (11\% v 2\%; adjusted risk difference $6.1 \%, 1.1 \%$ to $11.1 \%$ ) and less likely to die at home $(47 \% v 66 \% ;-10.8 \%,-1.0 \%$ to $-20.6 \%$ ), compared with those who were not. Patients who were receiving palliative chemotherapy on study enrollment were also less likely die in their preferred place, compared with those who were not $(68 \% v 80 \%$; adjusted risk difference $-9.4 \%$, $-0.8 \%$ to $-18.1 \%$ ). In a second model, we examined the association between palliative chemotherapy and patients' place of death without including characteristics that might change over time; our results were consistent, except that patients' likelihood of dying in their preferred place was no longer statistically significant $(\mathrm{P}=0.07)$.

\section{Discussion}

Our results suggest that terminally ill patients with advanced cancers who receive chemotherapy a few months before death are more likely to receive intensive care at the end of life, compared with patients who do not. In this study, the use of chemotherapy a median of 4.0 months before death was 
associated with an increased risk of undergoing mechanical ventilation, cardiopulmonary resuscitation, or both in the last week of life and of being referred to a hospice late, both of which have been associated with worse quality of life for patients at the end of life, ${ }^{11-30}$ more distress in bereaved caregivers, ${ }^{11} 29$ and higher costs. ${ }^{31}$ The use of palliative chemotherapy was also associated with an increased risk of dying in an intensive care unit, a decreased likelihood of dying at home, and a lower likelihood that patients died in their preferred place.

\section{Comparison with other studies}

This is the first study, to our knowledge, to examine the associations between the use of palliative chemotherapy and patients' location of death. Whereas previous studies have identified patient, caregiver, and system level factors that influence where cancer patients die, ${ }^{32-34}$ few have focused on how the care that terminally ill cancer patients receive in the final months of life relates to their place of death outside of hospice or palliative care settings. ${ }^{35}$

In this study, only a minority of terminally ill cancer patients preferred life extending medical care over care that focused on relieving pain and discomfort. However, more than half wanted chemotherapy if it would extend their life by one week, including $60 \%$ of patients who were not receiving chemotherapy. This finding is consistent with previous studies that have shown that many cancer patients are willing to undergo significant treatment related toxicities for small objective benefits. ${ }^{36}{ }^{37}$ The one week survival threshold for chemotherapy that we observed is significantly lower than the four to five month thresholds previously reported in similar populations of patients, ${ }^{37-39}$ and it suggests that cancer patients may not regard chemotherapy as burdensome because they are willing to receive it for very limited temporal pay-off.

Our findings also underscore the challenge that many oncologists face when discussing the option of stopping chemotherapy with patients and their caregivers, ${ }^{40}$ particularly when patients - and physicians - may equate stopping treatment with "giving up" or "doing nothing." ${ }^{41} 42$ In this study, we observed significant differences in the rates of use of chemotherapy by institution, although they were balanced after propensity weighting and therefore did not influence the observed associations between receipt of chemotherapy and patients' end of life medical care and place of death. Although our study could not directly compare the relative influences of patient, provider, and institution level factors, we suspect that a combination of these factors explains the differences observed. Future studies should examine the most important determinants of end of life use of chemotherapy.

In this study, we did not observe a difference in survival between patients who received palliative chemotherapy and those who did not. This should not be interpreted as evidence that palliative chemotherapy is futile in terminally ill cancer patients, as our analysis was limited to small sample of decedents and may have excluded patients who benefited most from chemotherapy. Instead, this finding should serve as a reminder that palliative chemotherapy does not necessarily extend life, but is associated with more intensive end of life care and increased risk of dying in an intensive care unit, so continuing treatment should not come at the cost of engaging in advance care planning. ${ }^{14} 15$

\section{Strengths and limitations}

This study has several important strengths. Previous studies have found that older patients who received chemotherapy within two weeks of death had higher rates of emergency department visits and hospital admissions and decreased hospice use at the end of life. ${ }^{6-43}$ Our data, collected more than a decade later, extend these results by examining associations between palliative chemotherapy given months before death, at the time when most decision making about chemotherapy occurs, and the intensity of patients' end of life medical care and place of death. Our study may also be more representative of the care provided to "dying patients" than previous work because it enrolled patients of all ages who were prospectively identified by their physicians as terminally ill with a prognosis of six months or less to live. ${ }^{44}{ }^{45}$ In addition, we had comprehensive data on patients' performance status, physical functioning, quality of life, and many other psychosocial factors associated with end of life decision making, including patients' treatment preferences, awareness of terminal illness, and end of life discussions with physicians, ${ }^{11-46}$ which are rarely available in other databases.

The study also has limitations. Most notably, we did not have any information about the timing or nature of patients' decisions about treatment after study enrollment, except for the last week of life. However, subsequent decisions to resume or stop chemotherapy would minimize differences between the two groups, making detection of the effects observed less likely. Despite this, we observed significant associations between the use of palliative chemotherapy and the intensity of patients' end of life care and place of death, and our results did not change when we removed characteristics that often change in response to chemotherapy (such as quality of life and performance status) or disease progression (such as treatment preferences and awareness of terminal illness). However, the association between receipt of palliative chemotherapy and patients' preferred place of death became marginally significant in sensitivity analyses and when we included additional covariates in propensity weighted models; thus, future studies should confirm these results in larger populations.

In addition, we did not have information about patients' baseline preferences for the timing of referral to a hospice or place of death. Although short hospice stays - and treatment in an intensive care unit near death-may be viewed as beneficial to dying patients or their family caregivers, ${ }^{47}$ our previous work suggests that for most patients these outcomes are associated with worse quality of life for patients and more distress in family caregivers six months after bereavement. ${ }^{11}{ }^{29}$ In addition, we did not randomize patients to receive palliative chemotherapy or not. Whereas propensity score weighting can effectively adjust for observed differences, it can adjust for unobserved confounders only if they are associated with observed confounders. Furthermore, patients who were receiving chemotherapy at enrollment may have differed in unmeasured ways from those who were not receiving chemotherapy (for example, in their disease duration or previous experiences with chemotherapy).

Finally, our analyses were limited to deceased patients who died in 2008 , and only a small proportion of our patients experienced the end of life outcomes of interest. Nevertheless, the frequency of events we observed is comparable to or higher than those from population based studies using the most recent Medicare claims available. For example, Teno et al found that $6.7 \%$ of cancer patients received mechanical ventilation in the last month of life in $2009 .{ }^{48}$ In our study, $8.5 \%$ of terminally ill cancer patients received mechanical ventilation or cardiopulmonary resuscitation in the last week of life, but a significant difference existed between groups $(13.9 \% v 1.6 \%)$ based on exposure to chemotherapy at baseline. Furthermore, we expect that our 
findings may be a conservative estimate, as Teno et al also found that the intensity of medical care near death is increasing over time. $^{48}$

\section{Conclusions and policy implications}

Our results suggest that less use of palliative chemotherapy among patients recognized to have a life expectancy of six months or less-or more frequent end of life discussions in this group - may reduce intensive end of life care and promote earlier access to hospice services, thus improving the quality of advanced cancer patients' end of life care. Future studies should determine the mechanisms by which palliative chemotherapy is associated with increased risk of receiving intensive care at the end of life and dying in an intensive care unit and examine explicitly whether palliative chemotherapy is associated with patients' goal attainment.

Our study has important implications for oncology providers, patients with advanced cancer, and caregivers facing decisions about treatment. It suggests that end of life discussions may be particularly important for patients receiving palliative chemotherapy, who should be informed by data on the likely outcomes associated with its use. The findings also suggest the need for oncology providers to elicit patients' preferred site of death to ensure that patients' end of life experiences are congruent with their values.

Contributors: AAW and HGP were responsible for the study concept and design. AAW, HGP BZ, NLK, and JCW analyzed and interpreted the data. AAW drafted the manuscript and all authors revised it for important intellectual content. AAW, BZ, NLK, and HGP approved the final manuscript, had full access to all of the data in the study, and take responsibility for the integrity of the data and the accuracy of the data analysis. HGP is the guarantor.

Funding: HGP has received research grants MH63892 from the National Institute of Mental Health and CA 106370 and CA 156732 from the National Cancer Institute; AAW has received research grants $1 \mathrm{~K} 07$ CA166210 from the National Cancer Institute and MRSG-13-013 from the American Cancer Society and a Conquer Cancer Foundation of American Society for Clinical Oncology Career Development Award; NLK received research grant 1 R01 CA164021 from the National Cancer Institute. The funding organizations had no role in the design and conduct of the study; collection, analysis, or preparation of the data; or preparation, review, or approval of the manuscript. Any opinions, findings, and conclusions expressed in this material are those of the authors and do not necessarily reflect those of the American Cancer Society, the American Society of Clinical Oncology, or the Conquer Cancer Foundation.

Competing interests: All authors have completed the ICJME uniform disclosure form at www.icmje.org/coi_disclosure.pdf (available on request from the corresponding author) and declare: HGP has received research grants from the National Institute of Mental Health and the National Cancer Institute; AAW has received research grants from the National Cancer Institute and the American Cancer Society and a Conquer Cancer Foundation of American Society for Clinical Oncology Career Development Award; NLK received a research grant from the National Cancer Institute; no financial relationships with any organizations that might have an interest in the submitted work in the previous three years; no other relationships or activities that could appear to have influence the submitted work.

Ethical approval: The study received approval from the human subjects committees of all participating centers. All patients gave written informed consent.

Transparency declaration: HGP affirms that the manuscript is an honest, accurate, and transparent account of the study being reported; that no important aspects of the study have been omitted; and that any discrepancies from the study as planned have been explained.

Data sharing: Specific assessments, statistical code, and the dataset are available on request from the corresponding author at hgp2001@med.cornell.edu.

1 Emanuel EJ, Young-Xu Y, Levinsky NG, Gazelle G, Saynina O, Ash AS. Chemotherapy use among Medicare beneficiaries at the end of life. Ann Intern Med 2003;138:639-43. 2 Braga S. Why do our patients get chemotherapy until the end of life? Ann Oncol 2011;22:2345-8.

3 Schnipper LE, Smith TJ, Raghavan D, Blayney DW, Ganz PA, Mulvey TM, et al. American Society of Clinical Oncology identifies five key opportunities to improve care and reduce costs: the top five list for oncology. $J$ Clin Oncol 2012;30:1715-24.

4 Harrington SE, Smith TJ. The role of chemotherapy at the end of life: "when is enough, enough?". JAMA 2008;299:2667-78.

5 Anders CK, Peppercorn J. Treating in the dark: unanswered questions on costs and benefits of late line therapy for metastatic breast cancer. Cancer Invest 2009;27:13-6.

6 Earle CC, Landrum MB, Souza JM, Neville BA, Weeks JC, Ayanian JZ. Aggressiveness of cancer care near the end of life: is it a quality-of-care issue? J Clin Oncol 2008;26:3860-6.

7 Saito AM, Landrum MB, Neville BA, Ayanian JZ, Earle CC. The effect on survival of continuing chemotherapy to near death. BMC Palliat Care 2011;10:14

8 Morden NE, Chang CH, Jacobson JO, Berke EM, Bynum JP, Murray KM, et al. End-of-life care for Medicare beneficiaries with cancer is highly intensive overall and varies widely. Health Aff (Millwood) 2012;31:786-96.

9 Greer JA, Pirl WF, Jackson VA, Muzikansky A, Lennes IT, Heist RS, et al. Effect of early palliative care on chemotherapy use and end-of-life care in patients with metastatic non-small-cell lung cancer. J Clin Oncol 2012;30:394-400.

10 Temel JS, Greer JA, Muzikansky A, Gallagher ER, Admane S, Jackson VA, et al. Early palliative care for patients with metastatic non-small-cell lung cancer. N Engl J Med 2010;363:733-42.

11 Wright AA, Zhang B, Ray A, Mack JW, Trice E, Balboni T, et al. Associations between end-of-life discussions, patient mental health, medical care near death, and caregiver bereavement adjustment. JAMA 2008;300:1665-73.

12 Wright AA, Katz IT. Letting go of the rope-aggressive treatment, hospice care, and open access. N Engl J Med 2007:357:324-7.

13 Aldridge Carlson MD, Barry CL, Cherlin EJ, McCorkle R, Bradley EH. Hospices' enrollment policies may contribute to underuse of hospice care in the United States. Health Aff (Millwood) 2012;31:2690-8.

14 Keating NL, Landrum MB, Rogers SO Jr, Baum SK, Virnig BA, Huskamp HA, et al. Physician factors associated with discussions about end-of-life care. Cancer 2010;116:998-1006.

15 Helft PR. Necessary collusion: prognostic communication with advanced cancer patients. $J$ Clin Oncol 2005;23:3146-50

16 Huskamp HA, Keating NL, Malin JL, Zaslavsky AM, Weeks JC, Earle CC, et al. Discussions with physicians about hospice among patients with metastatic lung cancer. Arch Intern Med 2009;169:954-62.

17 Sulmasy DP, Astrow AB, He MK, Seils DM, Meropol NJ, Micco E, et al. The culture of faith and hope: patients' justifications for their high estimations of expected therapeutic benefit when enrolling in early phase oncology trials. Cancer 2010;116:3702-11.

18 Karnofsky DA. Determining the extent of the cancer and clinical planning for cure. Cancer 1968;22:730-4.

19 Charlson ME, Pompei P, Ales KL, MacKenzie CR. A new method of classifying prognostic comorbidity in longitudinal studies: development and validation. J Chronic Dis 1987;40:373-83.

20 Carver CS. You want to measure coping but your protocol's too long: consider the brief COPE. Int J Behav Med 1997;4:92-100.

21 Fried TR, Bradley EH, Towle VR. Assessment of patient preferences: integrating treatments and outcomes. J Gerontol B Psychol Sci Soc Sci 2002;57:S348-54

22 Weeks JC, Cook EF, O'Day SJ, Peterson LM, Wenger N, Reding D, et al. Relationship between cancer patients' predictions of prognosis and their treatment preferences. JAMA 1998;279:1709-14

23 Prigerson HG. Socialization to dying: social determinants of death acknowledgement and treatment among terminally ill geriatric patients. J Health Soc Behav 1992;33:378-95.

24 Pargament KI, Koenig HG, Perez LM. The many methods of religious coping: development and initial validation of the RCOPE. J Clin Psychol 2000;56:519-43.

25 Mack JW, Block SD, Nilsson M, Wright A, Trice E, Friedlander R, et al. Measuring therapeutic alliance between oncologists and patients with advanced cancer: the Human Connection Scale. Cancer 2009;115:3302-11.

26 Lavori PW, Dawson R, Shera D. A multiple imputation strategy for clinical trials with truncation of patient data. Stat Med 1995;14:1913-25.

27 Rosenbaum PR, Rubin DB. Reducing bias in observational studies using subclassification on the propensity score. J Am Stat Assoc 1984;79:516-24.

28 Li F, Zaslavsky AM, Landrum MB. Propensity score weighting with multilevel data. Stat Med 2013;32:3373-87.

29 Wright AA, Keating NL, Balboni TA, Matulonis UA, Block SD, Prigerson HG. Place of death: correlations with quality of life of patients with cancer and predictors of bereaved caregivers' mental health. J Clin Oncol 2010;28:4457-64.

30 Teno JM, Clarridge BR, Casey V, Welch LC, Wetle T, Shield R, et al. Family perspectives on end-of-life care at the last place of care. JAMA 2004;291:88-93.

31 Kelley AS, Deb P, Du Q, Aldridge Carlson MD, Morrison RS. Hospice enrollment saves money for Medicare and improves care quality across a number of different lengths-of-stay. Health Aff (Millwood) 2013;32:552-61.

32 Gomes B, Higginson IJ. Factors influencing death at home in terminally ill patients with cancer: systematic review. BMJ 2006;332:515-21.

33 Alonso-Babarro A, Bruera E, Varela-Cerdeira M, Boya-Cristia MJ, Madero R, Torres-Vigil $\mathrm{I}$, et al. Can this patient be discharged home? Factors associated with at-home death among patients with cancer. J Clin Oncol 2011;29:1159-67.

34 Jeurkar N, Farrington S, Craig TR, Slattery J, Harrold JK, Oldanie B, et al. Which hospice patients with cancer are able to die in the setting of their choice? Results of a retrospective cohort study. J Clin Oncol 2012;30:2783-7. 


\section{What is already known on this topic}

Many patients with metastatic cancer receive chemotherapy in the final months of life, but most are not provided with information on the likely effect on their survival, future care and quality of life, and location of death

Retrospective, population based studies suggest that cancer patients who receive chemotherapy within two weeks of death are less likely to receive hospice services, compared with those who do not

Few studies have examined prospectively whether the use of chemotherapy months before death is associated with terminally ill cancer patients' end of life medical care and place of death

\section{What this study adds}

The use of chemotherapy in terminally ill adult cancer patients in the final months of life is associated with increased risk of undergoing intensive medical care near death and dying in an intensive care unit

Cancer patients, caregivers, and oncologists should have a heightened awareness about the potential risks of continuing palliative chemotherapy near death

Advance care planning is needed to ensure that patients' end of life experiences are congruent with their values

35 Carlson MD, Herrin J, Du Q, Epstein AJ, Barry CL, Morrison RS, et al. Impact of hospice disenrollment on health care use and medicare expenditures for patients with cancer. $J$ Clin Oncol 2010;28:4371-5.

36 Matsuyama R, Reddy S, Smith TJ. Why do patients choose chemotherapy near the end of life? A review of the perspective of those facing death from cancer. $J$ Clin Oncol 2006:24:3490-6.

37 Slevin ML, Stubbs L, Plant HJ, Wilson P, Gregory WM, Armes PJ, et al. Attitudes to chemotherapy: comparing views of patients with cancer with those of doctors, nurses, and general public. BMJ 1990;300:1458-60.

38 Silvestri G, Pritchard R, Welch HG. Preferences for chemotherapy in patients with advanced non-small cell lung cancer: descriptive study based on scripted interviews. $B M J$ 1998:317:771-5.

39 Donovan KA, Greene PG, Shuster JL, Partridge EE, Tucker DC. Treatment preferences in recurrent ovarian cancer. Gynecol Oncol 2002;86:200-11.

40 Cavalli-Bjorkman N, Glimelius B, Strang P. Equal cancer treatment regardless of education level and family support? A qualitative study of oncologists' decision-making. BMJ Open 2012;2:e001248.

41 Buiting HM, Rurup ML, Wijsbek H, van Zuylen L, den Hartogh G. Understanding provision of chemotherapy to patients with end stage cancer: qualitative interview study. BMJ 2011;342:d1933.

42 De Haes $\mathrm{H}$, Koedoot N. Patient centered decision making in palliative cancer treatment: a world of paradoxes. Patient Educ Couns 2003;50:43-9.

43 Earle CC, Neville BA, Landrum MB, Ayanian JZ, Block SD, Weeks JC. Trends in the aggressiveness of cancer care near the end of life. J Clin Oncol 2004;22:315-21.
44 Bach PB, Schrag D, Begg CB. Resurrecting treatment histories of dead patients: a study design that should be laid to rest. JAMA 2004;292:2765-70.

45 Earle CC, Ayanian JZ. Looking back from death: the value of retrospective studies of end-of-life care. J Clin Oncol 2006:24:838-40.

46 Weeks JC, Catalano PJ, Cronin A, Finkelman MD, Mack JW, Keating NL, et al. Patients' expectations about effects of chemotherapy for advanced cancer. N Engl J Med 2012;367:1616-25

47 Teno JM, Casarett D, Spence C, Connor S. It is "too late" or is it? Bereaved family member perceptions of hospice referral when their family member was on hospice for seven days or less. J Pain Symptom Manage 2012;43:732-8.

48 Teno JM, Gozalo PL, Bynum JP, Leland NE, Miller SC, Morden NE, et al. Change in end-of-life care for Medicare beneficiaries: site of death, place of care, and health care transitions in 2000, 2005, and 2009. JAMA 2013;309:470-7.

\section{Accepted: 27 January 2014}

\section{Cite this as: BMJ 2014;348:g1219}

This is an Open Access article distributed in accordance with the Creative Commons Attribution Non Commercial (CC BY-NC 3.0) license, which permits others to distribute, remix, adapt, build upon this work non-commercially, and license their derivative works on different terms, provided the original work is properly cited and the use is non-commercial. See: http://creativecommons.org/licenses/by-nc/3.0/. 


\section{Tables}

Table 1| Participants' characteristics by chemotherapy at study enrollment. Values are numbers (percentages) unless stated otherwise

\begin{tabular}{|c|c|c|c|c|c|c|c|}
\hline \multirow[b]{3}{*}{ Baseline characteristic ${ }^{\star}$} & \multirow{3}{*}{$\begin{array}{l}\text { All participants } \\
\quad(n=386)\end{array}$} & \multicolumn{3}{|c|}{ Before propensity weighted adjustment } & \multicolumn{3}{|c|}{ After propensity weighted adjustment } \\
\hline & & \multicolumn{2}{|c|}{ Chemotherapy } & \multirow[b]{2}{*}{$P$ value } & \multicolumn{2}{|c|}{ Chemotherapy } & \multirow[b]{2}{*}{$P$ value } \\
\hline & & Yes $(n=216)$ & No $(n=170)$ & & Yes $(n=216)$ & No $(n=170)$ & \\
\hline Mean (SD) age, years & $58.4(12.5)$ & $56.4(12.3)$ & $61.0(12.5)$ & $<0.001$ & $57.9(11.9)$ & $57.9(12.2)$ & $>0.9$ \\
\hline Male sex & $215(56)$ & $119(55)$ & $96(56)$ & 0.8 & $(55.8)$ & $(55.8)$ & $>0.9$ \\
\hline Married & $236(61)$ & $142(66)$ & $94(55)$ & 0.04 & $(58.0)$ & $(58.0)$ & 0.8 \\
\hline Insured & $238(62)$ & $145(67)$ & $93(55)$ & 0.02 & (55.9) & (55.8) & 0.8 \\
\hline $\begin{array}{l}\text { Mean (SD) years of } \\
\text { education }\end{array}$ & $12.6(4.0)$ & $13.3(3.9)$ & $11.6(4.0)$ & $<0.001$ & $11.9(4.1)$ & $11.9(4.2)$ & $>0.9$ \\
\hline Race/ethnicity: & & & & 0.1 & & & 0.7 \\
\hline White & $251(65)$ & $147(68)$ & $104(61)$ & & $(58.7)$ & $(58.7)$ & \\
\hline Black & $70(18)$ & $36(17)$ & $34(20)$ & & $(22.1)$ & $(22.1)$ & \\
\hline Hispanic & $57(15)$ & $26(12)$ & $31(18)$ & & $(18.4)$ & (18.4) & \\
\hline Asian & $5(1)$ & $5(2)$ & $0(0)$ & & $(0.7)$ & $(0.0)$ & \\
\hline Religion: & & & & 0.5 & & & $>0.9$ \\
\hline Catholic & $141(36)$ & $76(35)$ & $65(38)$ & & $(34.6)$ & $(34.6)$ & \\
\hline Protestant & $68(18)$ & $42(19)$ & $26(15)$ & & $(16.0)$ & $(16.0)$ & \\
\hline Jewish & $18(5)$ & $14(6)$ & $4(2)$ & & (3.4) & $(3.4)$ & \\
\hline Muslim & $5(1)$ & $3(1)$ & $2(1)$ & & $(0.7)$ & $(0.7)$ & \\
\hline No religion & $17(4)$ & $8(4)$ & $9(5)$ & & $(6.1)$ & $(5.0)$ & \\
\hline Pentecostal & $9(2)$ & $6(3)$ & $3(2)$ & & (3.7) & $(1.7)$ & \\
\hline Baptist & $58(15)$ & $29(13)$ & $29(17)$ & & $(17.0)$ & (19.5) & \\
\hline Institution: & & & & $<0.001$ & & & $>0.9$ \\
\hline Yale Cancer Center & $75(19)$ & $58(27)$ & $17(10)$ & & (17.8) & $(17.8)$ & \\
\hline Veterans Affairs CCC & $19(5)$ & $8(4)$ & $11(6)$ & & (5.7) & $(5.7)$ & \\
\hline $\begin{array}{l}\text { Parkland and Simmons } \\
\text { Cancer Center }\end{array}$ & $188(49)$ & $106(49)$ & $82(48)$ & & (53.3) & $(52.8)$ & \\
\hline MSKCC & $28(7)$ & $26(12)$ & $2(1)$ & & (3.3) & (3.3) & \\
\hline $\begin{array}{l}\text { Dana-Farber and } \\
\text { Massachusetts General }\end{array}$ & $7(2)$ & $3(1)$ & $4(2)$ & & (3.1) & $(3.1)$ & \\
\hline $\begin{array}{l}\text { New Hampshire Oncology } \\
\text { Hematology }\end{array}$ & $67(17)$ & $14(6)$ & $53(31)$ & & (16.6) & (16.6) & \\
\hline Cancer: & & & & 0.02 & & & 0.9 \\
\hline Lung & $85(22)$ & $43(20)$ & $42(25)$ & & $(23.7)$ & $(28.2)$ & \\
\hline Pancreatic & $36(9)$ & $27(13)$ & $9(5)$ & & $(8.4)$ & $(8.4)$ & \\
\hline Colorectal & $57(15)$ & $38(18)$ & $19(11)$ & & $(14.5)$ & $(14.5)$ & \\
\hline Other gastrointestinal & $57(15)$ & $27(13)$ & $30(18)$ & & (13.4) & (13.4) & \\
\hline Breast & $42(11)$ & $27(13)$ & $15(9)$ & & (12.4) & $(9.5)$ & \\
\hline Other† & $110(29)$ & $54(25)$ & $56(33)$ & & (27.5) & (27.5) & \\
\hline
\end{tabular}

Mean (SD) performance

statusł:

\begin{tabular}{lccccccc}
\hline Karnofsky score & $64.8(16.2)$ & $69.0(14.8)$ & $59.5(16.4)$ & $<0.001$ & $64.5(12.7)$ & $65.3(18.2)$ & 0.6 \\
\hline ECOG score & $1.7(0.9)$ & $1.5(0.9)$ & $2.0(0.9)$ & $<0.001$ & $1.7(0.7)$ & $1.7(0.9)$ & 0.9 \\
\hline $\begin{array}{l}\text { Charlson Comorbidity } \\
\text { Index }\end{array}$ & $8.3(2.7)$ & $7.9(2.3)$ & $8.8(3.0)$ & 0.002 & $8.3(2.4)$ & $8.3(2.7)$ & 0.8 \\
\hline $\begin{array}{l}\text { Mean (SD) McGill Quality } \\
\text { of Life§: }\end{array}$ & & & & & & \\
\hline Physical functioning & $5.7(2.6)$ & $6.1(2.4)$ & $5.3(2.9)$ & 0.004 & $5.7(2.3)$ & $5.6(3.0)$ & $>0.9$ \\
\hline Symptoms & $5.4(2.1)$ & $5.8(2.0)$ & $4.9(2.1)$ & $<0.001$ & $5.3(1.8)$ & $5.3(2.2)$ & $>0.9$ \\
\hline
\end{tabular}


Table 1 (continued)

\begin{tabular}{|c|c|c|c|c|c|c|c|}
\hline \multirow[b]{3}{*}{ Baseline characteristic ${ }^{*}$} & \multirow{3}{*}{$\begin{array}{l}\text { All participants } \\
\quad(n=386)\end{array}$} & \multicolumn{3}{|c|}{ Before propensity weighted adjustment } & \multicolumn{3}{|c|}{ After propensity weighted adjustment } \\
\hline & & \multicolumn{2}{|c|}{ Chemotherapy } & \multirow[b]{2}{*}{$P$ value } & \multicolumn{2}{|c|}{ Chemotherapy } & \multirow[b]{2}{*}{$P$ value } \\
\hline & & Yes $(n=216)$ & No $(n=170)$ & & Yes $(n=216)$ & No $(n=170)$ & \\
\hline Psychological: & $7.2(2.5)$ & $7.6(2.4)$ & $6.7(2.6)$ & 0.002 & $7.2(2.5)$ & $7.2(2.6)$ & $>0.9$ \\
\hline Depressed & $7.4(2.9)$ & $7.7(2.7)$ & $7.0(3.2)$ & 0.03 & $6.3(2.9)$ & $6.3(3.3)$ & $>0.9$ \\
\hline Worried & $6.9(3.2)$ & $7.2(3.0)$ & $6.4(3.3)$ & 0.01 & $6.8(3.1)$ & $6.8(3.6)$ & $>0.9$ \\
\hline Sad & $7.3(3.0)$ & $7.9(2.7)$ & $6.4(3.2)$ & $<0.001$ & $6.3(3.0)$ & $6.3(3.1)$ & $>0.9$ \\
\hline Terrified & $7.2(3.1)$ & $7.4(2.8)$ & $7.0(3.4)$ & 0.2 & $6.3(2.9)$ & $6.3(3.5)$ & $>0.9$ \\
\hline Support & $8.6(1.6)$ & $8.6(1.7)$ & $8.7(1.6)$ & 0.9 & $8.7(1.6)$ & $8.6(1.7)$ & 0.5 \\
\hline Sum score of quality of life & $6.8(1.5)$ & $7.0(1.4)$ & $6.6(1.6)$ & 0.002 & $6.8(1.4)$ & $6.8(1.6)$ & $>0.9$ \\
\hline \multicolumn{8}{|l|}{$\begin{array}{l}\text { Treatment preferences and } \\
\text { planning: }\end{array}$} \\
\hline $\begin{array}{l}\text { Wants prognostic } \\
\text { information }\end{array}$ & $269(69)$ & $152(70)$ & $117(69)$ & 0.8 & (74.4) & $(74.0)$ & 0.9 \\
\hline $\begin{array}{l}\text { Life extending care over } \\
\text { comfort care }\end{array}$ & $129(31)$ & $85(37)$ & $44(24)$ & 0.01 & (29.9) & $(29.1)$ & 0.9 \\
\hline $\begin{array}{l}\text { Chemotherapy to extend } \\
\text { life by } 1 \text { week }\end{array}$ & $288(77)$ & $186(89)$ & $102(62)$ & $<0.001$ & (79.9) & (79.2) & - \\
\hline $\begin{array}{l}\text { Wants to avoid dying in } \\
\text { ICU }\end{array}$ & $161(39)$ & $76(33)$ & $85(47)$ & 0.1 & $(37.4)$ & (37.8) & 0.9 \\
\hline $\begin{array}{l}\text { Completed living will or } \\
\text { DPA }\end{array}$ & $214(55)$ & $111(51)$ & $103(61)$ & 0.1 & $(52.5)$ & $(53.0)$ & $>0.9$ \\
\hline Completed DNR order & $161(42)$ & $77(36)$ & $84(49)$ & $<0.05$ & $(40.4)$ & $(40.4)$ & 0.8 \\
\hline $\begin{array}{l}\text { Terminal illness } \\
\text { acknowledgment }\end{array}$ & $159(40)$ & $76(35)$ & $83(47)$ & 0.04 & (39.3) & (39.6) & $>0.9$ \\
\hline \multicolumn{8}{|l|}{$\begin{array}{l}\text { Patient-physician } \\
\text { communication: }\end{array}$} \\
\hline $\begin{array}{l}\text { Therapeutic alliance with } \\
\text { physician }\end{array}$ & $244(64)$ & $131(62)$ & $113(67)$ & 0.3 & (64.4) & (64.6) & $>0.9$ \\
\hline $\begin{array}{r}\text { Discussed end of life } \\
\text { wishes with physician }\end{array}$ & $162(42)$ & $80(37)$ & $82(48)$ & 0.03 & $(40.4)$ & $(40.4)$ & $>0.9$ \\
\hline \multicolumn{8}{|l|}{ Coping style: } \\
\hline Active & $177(46)$ & $105(49)$ & $72(42)$ & 0.3 & $(44.7)$ & $(47.1)$ & 0.6 \\
\hline Emotional & $190(49)$ & $106(49)$ & $84(49)$ & $>0.9$ & $(50.0)$ & $(48.7)$ & 0.8 \\
\hline Behavioral disengagement & $82(21)$ & $31(14)$ & $51(30)$ & $<0.001$ & $(21.3)$ & $(25.7)$ & 0.3 \\
\hline $\begin{array}{l}\text { Mean (SD) positive religious } \\
\text { coping }\end{array}$ & $11.2(6.4)$ & $11.3(6.3)$ & $11.0(6.5)$ & 0.6 & $11.4(6.1)$ & $11.8(7.0)$ & 0.6 \\
\hline
\end{tabular}

$\mathrm{CCC}=$ Comprehensive Cancer Clinics; DNR=do not resuscitate; DPA=durable power of attorney; ECOG=Eastern Cooperative Oncology Group; ICU=intensive care unit; MSKCC=Memorial Sloan Kettering Cancer Center.

*Missing data: age $(n=2)$, male sex $(n=2)$, married $(n=6)$, insurance $(n=10)$, education $(n=2)$, race/ethnicity $(n=2)$, religion $(n=2)$, Karnofsky score $(n=20)$, ECOG score $(n=8)$, Charlson Comorbidity Index $(n=8)$, McGill Quality of Life $(n=4)$, prognostic information $(n=34)$, chemotherapy to extend life by 1 week ( $n=42)$, avoid death in ICU $(n=40)$, living will or DPA $(n=40)$, DNR order $(n=38)$, terminal illness acknowledgment $(n=40)$, therapeutic alliance with physician ( $n=31)$, end of life wishes $(n=1)$, positive religious coping $(n=51)$; multiple imputation was used to impute missing values in propensity weighted sample.

†Remaining patients had cancers that each represented $\leq 5 \%$ of sample.

¥Karnofsky score is a measure of functional status that is predictive of survival ( $0=$ dead and $100=$ perfect health); ECOG score is a measure of functional status $(0=$ asymptomatic and $5=$ dead); Charlson comorbidity index is an age adjusted measure of comorbid illness (higher numbers signify greater burden).

$\S$ Subscales of McGill Quality of Life Questionnaire (scale 0-10), where 0 is undesirable and 10 is desirable; for consistency, individual items where 10 indicated undesirable states (for example, $0=$ not at all depressed and $10=$ extremely depressed) were re-scaled. 
Table 2| Associations between chemotherapy at study enrollment and intensity of end of life care. Values are numbers (percentages) unless stated otherwise

\begin{tabular}{|c|c|c|c|c|c|c|c|}
\hline \multirow{3}{*}{$\begin{array}{l}\text { Medical care in last } \\
\text { week }^{\star}\end{array}$} & \multicolumn{3}{|c|}{ Unadjusted analysis } & \multicolumn{4}{|c|}{ Propensity weighted adjusted analysis } \\
\hline & \multicolumn{2}{|c|}{ Chemotherapy at enrollment } & \multirow{2}{*}{$\begin{array}{l}\text { Risk difference } \\
\qquad(95 \% \mathrm{Cl})\end{array}$} & \multicolumn{2}{|c|}{ Chemotherapy at enrollment } & \multirow{2}{*}{$\begin{array}{l}\text { Risk difference } \\
(95 \% \mathrm{Cl})\end{array}$} & \multirow[b]{2}{*}{$P$ value } \\
\hline & Yes $(n=216)$ & No $(n=170)$ & & Yes & No & & \\
\hline $\begin{array}{l}\text { Cardiopulmonary } \\
\text { resuscitation, } \\
\text { ventilation, or both }\end{array}$ & $30(14)$ & $3(2)$ & $12.1(7.1$ to 17.1$)$ & $24(12)$ & $4(2)$ & $10.5(5.0$ to 15.5$)$ & $<0.001$ \\
\hline $\begin{array}{l}\text { Admission to intensive } \\
\text { care unit }\end{array}$ & $31(14)$ & $14(8)$ & $6.1(-0.2$ to 7.4$)$ & $26(13)$ & $15(8)$ & $5.6(-0.5$ to 11.7$)$ & 0.07 \\
\hline Chemotherapy & $16(7)$ & $8(5)$ & $2.7(-2.0$ to 7.4$)$ & $12(6)$ & $10(5)$ & $1.1(-3.6$ to 5.7$)$ & 0.7 \\
\hline $\begin{array}{l}\text { Feeding tube for } \\
\text { enteral nutrition }\end{array}$ & $23(11)$ & $9(5)$ & $5.3(-0.1$ to 10.7$)$ & $22(12)$ & $9(5)$ & $7.1(1.7$ to 12.5$)$ & 0.01 \\
\hline Hospice $\leq 1$ week & $113(54)$ & $61(37)$ & 17.6 (7.6 to 27.6$)$ & $96(52)$ & $70(38)$ & 13.6 (3.6 to 23.6$)$ & 0.008 \\
\hline
\end{tabular}

*Missing data: admission to intensive care unit ( $n=1$, no chemotherapy), feeding tube for enteral nutrition ( $n=4 ; n=1$ chemotherapy, $n=3$ no chemotherapy), and hospice $\leq 1$ week ( $n=12 ; n=8$ chemotherapy, $n=4$ no chemotherapy). 
Table 3| Associations between chemotherapy at study enrollment, place of death, and attainment of preferred place of death. Values are numbers (percentages) unless stated otherwise

\begin{tabular}{|c|c|c|c|c|c|c|c|}
\hline \multirow[b]{3}{*}{ Variable* } & \multicolumn{3}{|c|}{ Unadjusted analysis } & \multicolumn{4}{|c|}{ Propensity weighted adjusted analysis } \\
\hline & \multicolumn{2}{|c|}{ Chemotherapy at enrollment } & \multirow{2}{*}{$\begin{array}{l}\text { Risk difference }(95 \% \\
\mathrm{Cl})\end{array}$} & \multicolumn{2}{|c|}{ Chemotherapy at enrollment } & \multirow{2}{*}{$\begin{array}{l}\text { Risk difference }(95 \% \\
\mathrm{Cl})\end{array}$} & \multirow[b]{2}{*}{$P$ value } \\
\hline & Yes $(n=216)$ & No $(n=170)$ & & Yes & No & & \\
\hline \multicolumn{8}{|l|}{ Place of death: } \\
\hline Intensive care unit & $24(11)$ & $4(2)$ & $8.8(4.0$ to 13.6$)$ & $19(10)$ & $7(4)$ & $6.1(1.1$ to 11.1$)$ & 0.02 \\
\hline Hospital & $54(25)$ & $26(15)$ & $9.8(1.9$ to 17.8$)$ & $38(21)$ & $32(17)$ & $3.6(-4.1$ to 11.3$)$ & 0.4 \\
\hline Home & $102(47)$ & $112(66)$ & $-18.4(-8.7$ to -28.2$)$ & $100(52)$ & $122(63)$ & $-10.8(-1.0$ to -20.6$)$ & 0.03 \\
\hline Inpatient hospice & $28(13)$ & $19(11)$ & $-1.8(-4.7$ to -8.4$)$ & $26(13)$ & $22(12)$ & $2.0(-4.6$ to 8.7$)$ & 0.6 \\
\hline Nursing home & $7(3)$ & $9(5)$ & $-2.0(-6.2$ to 2.1$)$ & $7(4)$ & $9(5)$ & $1.0(-5.0$ to 3.1$)$ & 0.6 \\
\hline $\begin{array}{l}\text { Death in preferred } \\
\text { place }\end{array}$ & $140(65)$ & $135(80)$ & $-12.4(-3.6$ to -21.2$)$ & $131(68)$ & $154(80)$ & $-9.4(-0.8$ to -18.1$)$ & 0.03 \\
\hline
\end{tabular}

*Missing data: place of death ( $n=1$, chemotherapy), death in preferred place $(n=12 ; n=10$ chemotherapy, $n=2$ no chemotherapy). 